\title{
RESEARCH \\ A Tandem Duplication within the fibrillin 1 Gene Is Associated with the Mouse Tight skin Mutation
}

\section{Linda D. Siracusa, ${ }^{1,3}$ Rodney McGrath, ${ }^{2}$ Qing Ma, John J. Moskow, ${ }^{1}$ Jayanthi Manne, ${ }^{1}$ Paul J. Christner, ${ }^{2}$ Arthur M. Buchberg, ${ }^{1}$ and Sergio A. Jimenez ${ }^{2}$}

\footnotetext{
${ }^{1}$ Department of Microbiology and Immunology, Jefferson Cancer Center; ${ }^{2}$ Department of Medicine, Jefferson Medical College, Thomas Jefferson University, Philadelphia, Pennsylvania 19107-5541
}

\begin{abstract}
Mice carrying the Tight skin (Tsk) mutation have thickened skin and visceral fibrosis resulting from an accumulation of extracellular matrix molecules. These and other connective tissue abnormalities have made $T s k l+$ mice models for scleroderma, hereditary emphysema, and myocardial hypertrophy. Previously we localized Tsk to mouse chromosome 2 in a region syntenic with human chromosome 15. The microfibrillar glycoprotein gene, fibrillin I (FBNI), on human chromosome 15q, provided a candidate for the Tsk mutation. We now demonstrate that the Tsk chromosome harbors a 30- to 40-kb genomic duplication within the Fbnl gene that results in a larger than normal in-frame $\mathrm{Fbnl}$ transcript. These findings provide hypotheses to explain some of the phenotypic characteristics of $T s k /+$ mice and the lethality of $T s k / T s k$ embryos.
\end{abstract}

Tight skin (Tsk) is an autosomal dominant mutation that occurred spontaneously in the inbred mouse strain B10.D2 $(58 \mathrm{~N}) / \mathrm{Sn}$; the original mutant was detected because it displayed unusually tight skin in the interscapular region (Green et al. 1976). Heterozygous Tsk mice have thickened skin that is firmly bound to the subcutaneous and deep muscular tissues and that lacks the pliability and elasticity characteristic of normal skin. Excessive accumulation of several collagens and glycosaminoglycans occurs in various organs including the skin, heart, and lungs (for review, see Jimenez and Christner 1994). The Tsk mutation also results in larger skeletal size caused by excessive growth of bone and cartilage (Green et al. 1976). Homozygous Tsk embryos degenerate at 7-8 days of development, whereas Tsk heterozygotes have a normal life span (Green et al. 1976).

The Tsk mouse has been used as a model for several human diseases. The increased expression of collagens found in the enlarged heart make Tsk/+ mice models for the study of myocardial hypertrophy (Osborn et al. 1987; Chapman and

${ }^{3}$ Corresponding author.

E-MAIL siracusa@lac.jci.tju.edu; FAX 215-923-4153.
Eghbali 1990; Bashey et al. 1993). Heterozygous Tsk mice serve as a model for hereditary emphysema, a condition they develop by 1 month of age (Szapiel et al. 1981; Rossi et al. 1984; Gardi et al. 1989; Martorana et al. 1989). Tsk/+ mice have been proposed as models for the hereditary connective tissue disorder congenital fascial dystrophy (Jablonska et al. 1989), and other related stiff skin syndromes (Esterly and McKusick 1971; Singer et al. 1977; Stevenson et al. 1984). The Tsk mouse has also provided a model for systemic sclerosis or scleroderma (SSc) (for review, see Jimenez and Christner 1994), a connective tissue disease characterized by excessive extracellular matrix (ECM) deposition in skin and various internal organs (D'Angelo et al. 1969; Medsger 1993). The frequently progressive tissue fibrosis is largely responsible for the morbidity and mortality of patients with SSc. The fibrosis seen in tissues of $T s k /+$ mice (Osborn et al. 1987; Gardi et al. 1989; Longhurst et al. 1992) mimics the excessive accumulation of collagen responsible for the severe cutaneous and visceral fibrosis of patients with SSc (for review, see Medsger 1993). Therefore, the Tsk mutation provides a unique opportunity to investigate the pathogenesis of tissue fibrosis at the molecular level.

As a first step to identify the gene responsible 
for the Tsk phenotype, we and others mapped Tsk with respect to molecular markers (Siracusa et al. 1993; Doute and Clark 1994; Everett et al. 1994). The results localized Tsk to mouse chromosome 2, between $B 2 m$ and $I l 1 a$, in a region syntenic with human chromosome 15 . The gene encoding the microfibrillar glycoprotein fibrillin 1 (FBN1) resides within the syntenic region on human chromosome 15q21 (Lee et al. 1991; Magenis et al. 1991). Cytogenetic studies had shown that Fbn1 mapped to mouse chromosome 2, band F (Li et al. 1993) and previously we determined that Fbn1 lies between $B 2 m$ and $I l 1 a$ on mouse chromosome 2 , thus establishing its candidacy for the Tsk mutation (Goldstein et al. 1994). The product of the FBN1 locus is a large $350-\mathrm{kD}$ secreted glycoprotein that is an integral component of 10 - to $12-\mathrm{nm}$ noncollagenous microfibrils present in the ECM of many organs and tissues (Cleary and Gibson 1983). Fbn1 and the highly related Fbn2 proteins (Lee et al. 1991; Zhang et al. 1994) participate in microfibril assembly and provide a structural foundation for microfibril formation, acting as templates for tropoelastin deposition in elastic tissues, and providing anchoring roles in nonelastic tissues; the fibrillins participate in the biological functions of microfibrils, and may mediate protein-protein interactions or influence cell growth, or both (for review, see Corson et al. 1993; Ramirez et al. 1993). Mutations in FBN1 have been identified in patients with Marfan syndrome (MFS), a heritable connective tissue disease that affects primarily the cardiovascular, skeletal, and ocular systems (Marfan 1896; Dietz et al. 1991, 1992a,b; Kainulainen et al. 1992). In addition, mutations in FBN1 have been described in patients with ectopia lentis and in infants exhibiting a neonatal lethal form of MFS (Kainulainen et al. 1994; Milewicz and Duvic 1994). Mutations in the closely related $F B N 2$ gene have been identified in patients with congenital contractural arachnodactyly, a disorder similar to MFS (Putnam et al. 1995).

We now report that a duplication within the Fbn1 gene is associated with the Tsk mutation. The findings lead to hypotheses to explain the pleiotropic and diverse connective tissue alterations observed in heterozygous Tsk mice as well as the recessive lethality of homozygous Tsk embryos. The results suggest novel avenues to investigate molecular mechanisms associated with tissue fibrosis as well as the assembly, structure, and function of microfibrils.

\section{RESULTS}

\section{The Fbnl Gene Cosegregates with the Tsk Mutation}

We considered $F b n 1$ a candidate for $T s k$ based on its structure and function in connective tissue (for review, Ramirez et al. 1993) as well as on the finding of an accumulation of microfibrils in skin from $T s k /+$ mice compared to controls (Green et al. 1976). To investigate the genetic relationship of $F b n 1$ and $T s k$, we isolated mouse $F b n 1$ cDNA clones (Fig. 1) and mapped Fbn1 in an intersubspecific backcross involving Mus castaneus (CAST) and C57BL/6 (B6) $p a+/+$ Tsk mice (see Methods). Genomic DNA from $\mathrm{N}_{2}$ progeny carrying $T s k$ was subjected to Southern blot and PCR analyses to identify restriction fragment and simple sequence length polymorphisms (Siracusa et al. 1993). A 494-bp mouse Fbn1 cDNA probe (3' UTR) from the $3^{\prime}$-untranslated region (Fig. 1D) detected a 9.1-kb BclI fragment in B6 pa+l+ Tsk mice and a 6.8 -kb $B c l$ fragment in CAST mice. To establish the position of $F b n 1$ with respect to Tsk, we typed $132 \mathrm{~N}_{2}$ progeny for D2Mit63 and D2Mit19; the 4 recombinant and 13 randomly selected nonrecombinant $\mathrm{N}_{2}$ progeny were typed for $F b n 1$ (data not shown). The finding of no recombination between the Fbn1 and Tsk loci supported $F b n 1$ as a candidate for the Tsk mutation.

\section{A Mutant Fbnl Transcript Is Present in $T s k /+$ Mice}

We then examined Fbn1 expression in wild-type and mutant mouse tissues by screening total RNA with the M-4 probe (Fig. 2). A single transcript of $11 \mathrm{~kb}$ was detected in tissues of $\mathrm{B} 6++/++$ and $\mathrm{B} 6$ $p a+/ p a+$ mice. In contrast, two transcripts of 14 and $11 \mathrm{~kb}$ were detected in B6 $p a+/+T s k$ mice. To confirm that the alteration in Fbn1 expression was specific to mice carrying $T s k$, total lung RNA from B $6 p a+1+T s k$, B $6 p a+/ p a+$, and $(\mathrm{CAST} \times \mathrm{B} 6) \mathrm{F}_{1}+{ }^{\mathrm{c}}+\mathrm{c} \%+$ Tsk mice was hybridized with the M-4 probe (data not shown). The $14-\mathrm{kb}$ Fbn1 transcript was detected only in mice carrying Tsk, regardless of genetic background.

Northern blot analyses also revealed that the 14 -kb Tsk-specific transcript is detected in all tissues that normally express the 11-kb wild-type Fbn1 transcript. Expression levels of the mutant and wild-type $F b n 1$ transcripts appeared highest in skin, heart, and lungs, whereas expression levels of both transcripts were lower in brain and spleen (Fig. 2). These findings suggested that the Tsk mutation did not alter the regulation of the Fbn1 gene. Moreover, tissues that showed severe 
SIRACUSA EI AL.

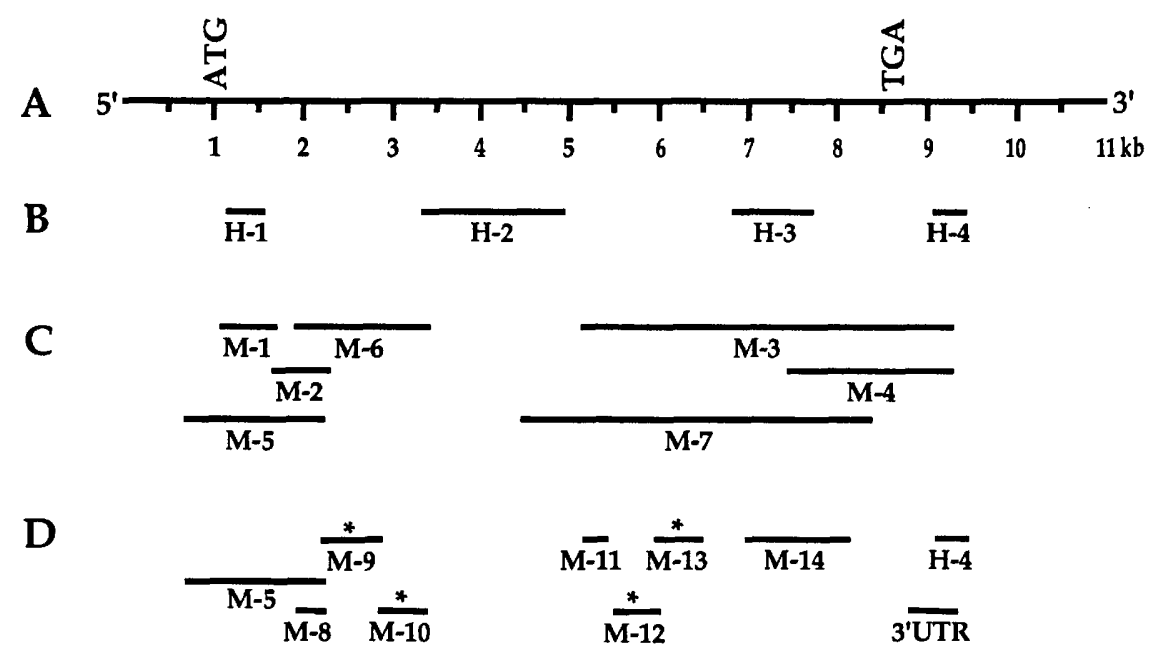

Figure 1 Diagram of human $F B N 1$ and mouse $F b n 1$ CDNA probes. $(A) \mathrm{A}$ diagram of the entire 11-kb mouse Fbn1 mRNA (Yin et al. 1995a). The FBN1 genomic locus encompasses $110 \mathrm{~kb}$ of DNA; 65 exons encode the human transcript, with most coding exons representing a specific repeated domain (Pereira et al. 1993). (B) Probes specific for the human FBN1 CDNA ( $\mathrm{H}-1$ to $\mathrm{H}-4)$ are described in Methods. Radiolabeled human probes were used to screen a mouse lung CDNA library (Stratagene). (C) The nucleotide coding and deduced amino acid sequences of our mouse $\mathrm{Fbn} 1 \mathrm{CDNA}$ clones (M-1 to $M-7$ ) showed $\geqslant 95 \%$ identity with human $F B N 1$ sequences (Maslen et al. 1991; Corson et al. 1993; Pereira et al. 1993). In addition, our mouse Fbn1 sequence is virtually identical to the published mouse sequence (Yin et al. 1995a). (D) Probes used to identify regions containing rearranged fragments; the asterisks denote those probes that identified rearranged fragments on the Tsk chromosome (see Results).

abnormalities in Tsk/+ mice (skin, heart, and lungs) also exhibited the highest levels of $F b n 1$ expression, supporting the hypothesis that the $T s k$-specific $F b n 1$ transcript may be associated with and/or contribute to Tsk phenotypes. These findings suggested that the normal 11-kb Fbn1 transcript originated from the wild-type chromosome, whereas the mutant 14-kb Fbn1 transcript originated from the Tsk chromosome.

\section{Pulsed-field Gel Electrophoresis Reveals a Rearrangement at the Fbnl Locus}

The physical relationship between the $F b n 1$ gene and the Tsk mutation was investigated by gel electrophoresis using contour-clamped homogeneous electric fields (CHEF). Genomic DNA from $T s k /+$ mice along with controls was digested with BssHII, EagI, NotI, or NruI and hybridized to Fbn1 cDNA probes from the $5^{\prime}$ UTR/promoter region, the central coding region, and the $3^{\prime}$ UTR (Fig. 3; data not shown). An abnormally large fragment was detected in $T s k /+$ mice with the probes from the central coding and $3^{\prime}$ UTR regions, but not with the probe from the $5^{\prime}$ UTR/ promoter region. The mutant fragment was 30-40 kb larger than that arising from the wild-type allele, regardless of the restriction endonuclease used. In addition, the mutant fragments detected by the central coding region probe appeared twice as intense as the wild-type fragments, whereas the same mutant fragments detected by the $3^{\prime}$ UTR probe appeared equal in intensity to the wild-type fragments (Fig. 3B,C). This finding suggested that a duplication involving the central coding region probe occurred within the Fbn 1 gene. Comparison of the physical maps for the + versus Tsk chromosome showed that although the BssHII, EagI, NruI, and NotI sites 3 ' to the Fbn1 locus are in identical positions with respect to each other, these sites are separated by an additional $30-40 \mathrm{~kb}$ in the Tsk chromosome (Fig. 3D). The data further supported a duplication within the $F b n 1$ gene and indicated that $30-40 \mathrm{~kb}$ of genomic DNA was involved. To confirm this hypothesis, we screened genomic DNA to define the limits of the putative duplicated region.

Identification of the Duplication Boundaries within the Fbnl Gene

Based on the finding that only the central coding region probe detected a duplication by CHEF gel electrophoresis (Fig. 3) and that the Tsk-specific transcript was $3 \mathrm{~kb}$ larger than the wild-type Fbn 1 transcript (see Fig. 2), we reasoned that the putative duplication must also involve $3 \mathrm{~kb}$ of $F b n 1$ coding sequences. Therefore, genomic DNA from control and Tsk mice was screened to identify $T s k$-specific restriction fragments by Southern blot analyses with probes derived from clones M-6 and M-7 (M-8 to M-13) that flanked both sides of the central coding region probe (see Fig. 1D). We also screened for rearrangements with 


\section{TANDEM DUPLICATION OF FBNI GENE IN TSK MICE}

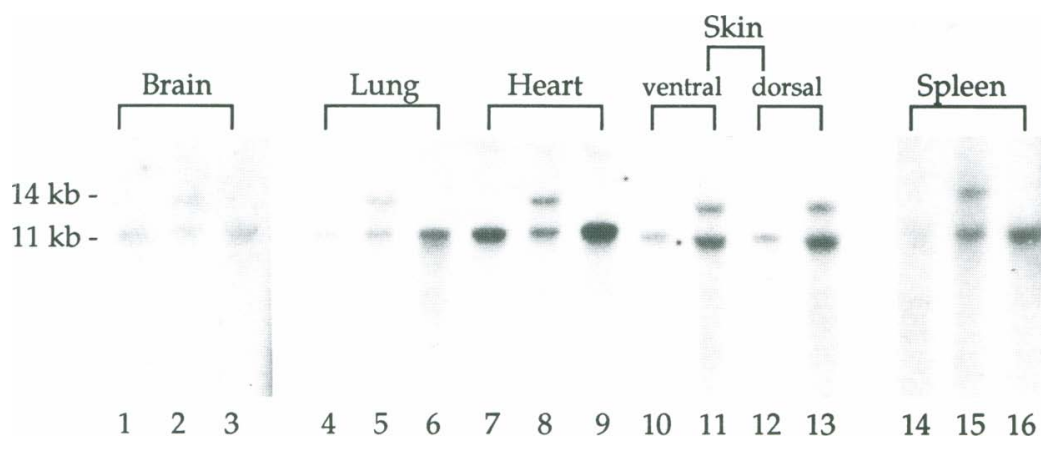

Figure 2 Northern blot analysis of $\mathrm{Fbn} 1$ expression in Tsk tissues. The expression pattern of Fbn 1 was studied in tissues from 5-week-old male $T s k /+$ mice compared to sex- and age-matched controls. Total RNA ( 10 $\mu \mathrm{g} /$ lane) from the tissues listed was hybridized with the $M-4$ probe. (Lanes 1,4,7,10,14) B6 ++/++ RNA; (lanes 2,5,8,11,13,15) B6 pa+l + Tsk RNA, and (lanes 3,6,9,12,16) B6 pa+/pa+RNA. The length of autoradiographic exposure for brain and spleen was four times that for lung, heart, and skin to enhance visualization of the low level of Fbn1 expression in these tissues.

probes that spanned most of the Fbn1 transcript (M-5, M-14, 3' UTR, H-4).

Southern blots of genomic DNA from mutant and wild-type mice digested with BamHI, BclI, BglI, DraI, EcoRI, EcoRV, HindIII, KpnI, MspI, PstI, SacI, TaqI, or XbaI were screened. Only four probes (M-9 and $\mathrm{M}-10, \mathrm{M}-12$ and $\mathrm{M}-13$ ) that spanned the Fbn1 transcript (representing bp 1156-2337 and 4419-5483, respectively) detected genomic alterations (Figs. 1A and 5a, below; Methods). Probe M-9 (representing bp 11561921) detected Tsk-specific fragments with $\mathrm{Hin}$ dIII and KpnI. Probe M-10 (representing bp 19042337) detected Tsk-specific fragments with $B a m H I, B c l$, HindIII, and KpnI. Probe M-12 (representing bp 4419-4971) detected Tsk-specific fragments with BamHI, Bcll, EcoRI, and KpnI. Probe M-13 (representing bp 4951-5483) detected $T s k$-specific fragments with all restriction endonucleases tested except $\mathrm{Xbal}$ (data not shown). The M-10 and M-13 probes detected identical Tsk-specific fragments with BamHI, BclI, $B g l I, H i n d I I I$, and KpnI, indicating that each fragment represented the single breakpoint junction diagnostic for a duplication.

To demonstrate that the mutant 7.0-kb HindIII fragment detected by $\mathrm{M}-10$ and $\mathrm{M}-13$ was $T s k$-specific and not the result of a polymorphism between strains, we hybridized both probes to genomic DNA from mutant and control mice (Fig. $4)$. The inbred strain B10.D2 $(58 \mathrm{~N}) / \mathrm{Sn}$ on which Tsk arose (Green et al. 1976) along with the pro- genitors (C57BL/10 and DBA/2J) of the B10.D2 $(58 \mathrm{~N}) / \mathrm{Sn}$ strain were tested in addition to CAST $+{ }^{\mathrm{c}} /+^{\mathrm{c}}$, $(\mathrm{CAST} \times \mathrm{B} 6) \mathrm{F}_{1}+{ }^{\mathrm{c}}+{ }^{\mathrm{c}} /+T s k, \mathrm{~B} 6 p a+1$ $+T s k, \mathrm{~B} 6++1++$, and $\mathrm{B} 6 \mathrm{pa}+1$ $\mathrm{pa}+$ mice. Both probes detected a mutant Tsk-specific 7.0-kb HindIII fragment; however, the wild-type fragments detected by each probe were different, as expected for a duplication (Fig. 4). Although the $\mathrm{M}-10$ and $\mathrm{M}-13$ probes are separated by 2614 bp in wild-type transcripts (corresponding to $30-40 \mathrm{~kb}$ of genomic DNA based on the human FBN1 gene) (Pereira et al. 1993), the probes reside in close proximity ( $\leqslant 7.0 \mathrm{~kb}$ ) on the Tsk chromosome. Furthermore, the autoradiographic intensities of the $7.0-\mathrm{kb}$ versus the 8.0 - or $8.3-\mathrm{kb}$ fragments detected with the M-10 probe (Fig. 4A) were consistent with a duplication that resulted in only one copy of the breakpoint junction fragment and two copies of the wild-type fragment, respectively. Thus, the duplication must have occurred between sequences residing upstream of the 3' end of probe M-10 (corresponding to bp 2337 ) and sequences residing downstream of the 5 ' end of probe M-12 (corresponding to bp 4419) of the Fbn1 coding region.

To confirm that the duplication breakpoint segregated concordantly with the Tsk mutation, we phenotyped and genotyped a total of 330 mice from the crosses listed in Table 1. Genomic DNA from these mice was digested with HindIII and typed by Southern blot analysis with the $\mathrm{M}-10$ probe. None of the 330 mice tested showed a recombination between the presence of the 7.0kb HindIII Fbn1 breakpoint junction fragment and the Tsk mutation.

\section{Sequence of the Tsk-specific Junction Fragment in Fbnl mRNA and Genomic DNA}

RT-PCR was used to amplify a predicted unique Tsk-specific cDNA fragment at the junction of duplicated $F b n 1$ coding segments. Primer B8 was used for the RT reaction because B8 resides just downstream of the $3^{\prime}$ end of the M-10 probe (Fig. 5a). Primers D5, D8, and D6 corresponding to sequences from the $\mathrm{M}-12$ probe (as well as primer D1 located upstream of M-12) were used for the PCR amplification, along with primer B2 corre- 


\section{SIRACUSA ET AL.}

A

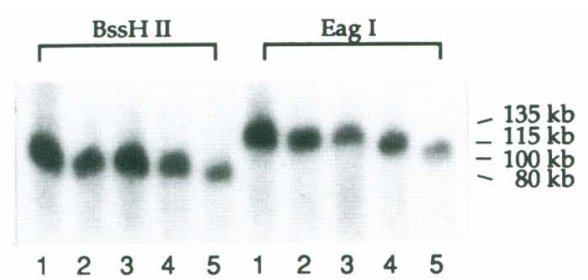

B

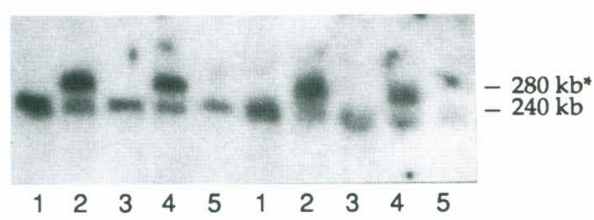

C

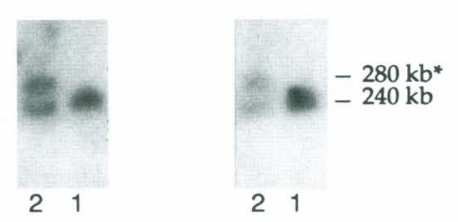

D
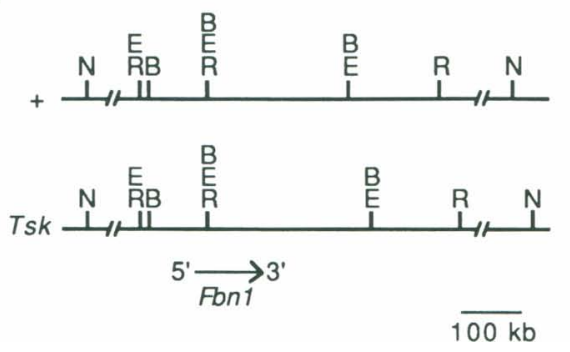

Figure 3 CHEF gel electrophoresis and a physical map of the genomic region containing the Fbn1 gene. (A) BssHII and Eagl were used to cleave genomic DNA from B6 $p a+/ p a+($ lane 1$)$, B6 pa+l+Tsk (lane 2), B6++/++(lane 3), $\left(\right.$ CAST $\times$ B6) $+{ }^{c}+c /+$ Tsk (lane 4$)$, and CAST $+^{c}++^{c} /+^{c}+{ }^{c}$ (lane 5) mice. The CHEF blots were hybridized with a $5^{\prime}$ UTR/promoter region probe $(-2290$ to $-1743 \mathrm{bp})(A)$, a central coding region probe (H-2 corresponding to bp 2353-3904) (B), and a $3^{\prime}$ UTR region probe (8683-9178 bp) (C). Size fragments are listed to the right. The asterisks indicate Tsk-specific fragments. (D) A physical map of the $F b n 1$ region was constructed by performing a series of double digestions of $\mathrm{B} 6 p a+/ p a+$ and $B 6$ $p a+/+T s k$ genomic DNA. The + represents the physical map of the wild-type chromosome; the Tsk represents the physical map of the Tsk chromosome. Shown below both maps is the region encoding the $F b n 1$ gene; the direction of transcription is indicated by the arrow. (B) BssHIl; (E) Eagl; (N) Notl; and (R) Nrul. Sequence analysis confirmed the presence of the $B, E, R$ site in the $5^{\prime}$ UTR region of the mouse Fbn1 gene (Yin et al. 1995a). The scale bar indicates the fragment sizes with the exception of Notl. The Notl fragment is $660 \mathrm{~kb}$ from the + chromosome and $690 \mathrm{~kb}$ from the Tsk chromosome.
A

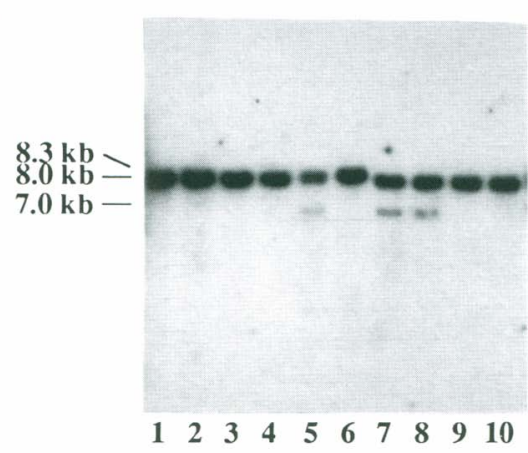

B

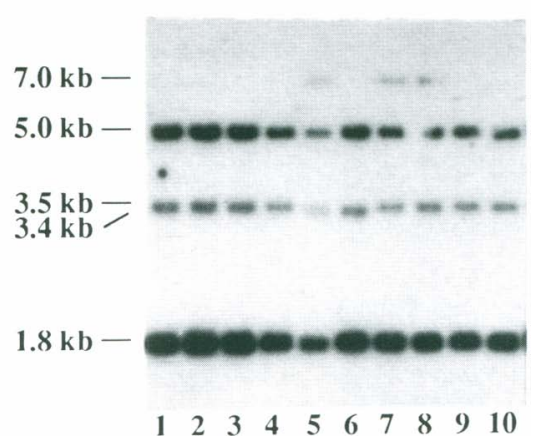

Figure 4 Identification of a mutant fragment with mouse Fbn 1 cDNA probes. Southern blots of HindIIIdigested mutant and control genomic DNAs were hybridized with a series of $F b n 1$ CDNA probes (Fig. 1D) including $\mathrm{M}-10(A)$ and $\mathrm{M}-13(B)$. (Lane 1) B10.D2(58N)/Sn male; (lane 2) B10.D2(58N)/Sn female; (lane 3) C57BL/10 I++/++ male; (lane 4) DBA/ 2) $++/++$ female; (lane 5) $\left(\right.$ CAST $\times$ B6) $\mathrm{F}_{1}+{ }^{\mathrm{c}}+{ }^{\mathrm{C}} /$ + Tsk female; (lane 6) CAST $++^{\mathrm{c}}+{ }^{\mathrm{C}} /+^{\mathrm{c}}+{ }^{\mathrm{c}}$ female; (lane 7) B6 $p a+/+$ Tsk female; (lane 8) B6 $p a+/+T s k$ male; (lane 9) B6 ++/++ female; and (lane 10) B6 $p a+/ p a+$ male. A Tsk-specific 7.0-kb fragment is detected by both probes, whereas an endogenous 8.0-kb fragment is detected by the M-10 probe and endogenous fragments of 5.0,3.5, and $1.8 \mathrm{~kb}$ are detected by the $\mathrm{M}-13$ probe in the inbred strains. CAST-specific fragments of $8.3,3.4$, and $1.8 \mathrm{~kb}$ are also detected. The $M-10$ and $M-13$ probes detect the same unique $T s k$-specific $7.0-\mathrm{kb}$ fragment consistent with an internal duplication within the Fbn1 gene.

sponding to sequences at the $3^{\prime}$ end of the M-10 probe (Fig. 5a). PCR primer pairs D1 and B2, D5 and B2, D8 and B2, and D6 and B2 (Fig. 5a) each amplified independently a unique fragment in B6 pa $+1+$ Tsk mice that was not detected in B6 $p a+1 p a+$ mice. Nucleotide sequencing revealed that the 870-bp fragment obtained with primers D6 and B2 contained sequences from two distinct 
TANDEM DUPLICATION OF FBNI GENE IN TSK MICE

\begin{tabular}{|c|c|c|}
\hline $\begin{array}{l}\text { Strains and genotypes } \\
\text { of progenitors }\end{array}$ & Type of cross & Number of progeny \\
\hline $\begin{array}{l}\mathrm{CAST} \times\left(\mathrm{CAST} \times \mathrm{B} 6 p a+/+T_{s k}\right) \mathrm{F}_{1} \\
\mathrm{~B} 6++/++\times \mathrm{B} 6+T s k /++ \\
\mathrm{B} 6 p a+/ p a+\times \mathrm{B} 6 p a T s k / p a+ \\
\mathrm{B} 6 p a+/ p a+\times \mathrm{B} 6 p a+/+T s k\end{array}$ & $\begin{array}{l}\text { backcross } \\
\text { backcross } \\
\text { intercross } \\
\text { intercross }\end{array}$ & $\begin{array}{r}168 \\
86 \\
32 \\
44\end{array}$ \\
\hline
\end{tabular}

regions of Fbn1 (Fig. 5). Because the intron/exon structure of the mouse $F b n 1$ gene is not known, we compared the junction fragment to the intron/exon structure of the human FBN1 gene (Pereira et al. 1993). The 5' portion of the junction fragment corresponded to exon 40 , whereas the $3^{\prime}$ portion corresponded to exon 17 , with the junction occurring between bp 5065 and 2113 of the Fbn 1 cDNA (Fig. 5b). The nucleotides of both exons remain intact at the junction, resulting in a mutant Fbn1 transcript that maintains the open reading frame and is 2952 bp larger than the wild-type Fbn1 transcript (Fig. 5b,c).

To determine the breakpoint in genomic DNA, long-range PCR was used to amplify introns 16 and 40 from the + chromosome and the intron between exons 40 and 17 from the Tsk chromosome (see Methods). Sequencing of the PCR products showed that the chromosomal break occurred within a 4 -bp sequence that is identical between intron 16 and intron 40 (Fig. 6 ). The recombination that resulted in the duplication occurred $150 \mathrm{bp}$ downstream of the splice donor site at the $3^{\prime}$ end of exon 40 and $3.4 \mathrm{~kb}$ upstream of the splice acceptor site at the 5 ' end of exon 17. Thus, the splice donor and acceptor sites between exons 40 and 17 have remained intact on the Tsk chromosome.

\section{DISCUSSION}

Our results show that the Tsk mutation is associated with an internal duplication within the Fbn1 gene. The $30-$ to $40-\mathrm{kb}$ genomic duplication results in a mutant Fbn1 transcript that is $3 \mathrm{~kb}$ larger than the wild-type transcript. The Tskspecific Fbn1 transcript contains a perfect inframe duplication of exons $17-40$, and is pre- dicted to encode a mutant $418-\mathrm{kD}$ polypeptide instead of the normal $312-\mathrm{kD}$ polypeptide. The deduced mutant Fbn1 protein would have one additional RGD domain, two additional TGFbinding protein $(\mathrm{bp})$ repeats, 18 additional EGF$\mathrm{CB}$ repeats, and one additional Fib motif in comparison to the wild-type Fbn1 protein (Fig. 7).

The tandem duplication within Fbn 1 does not appear to influence grossly the amount of normal or mutant $F b n 1$ transcripts, as evidenced by comparable steady-state levels of both transcripts in Tsk/+ tissues (Fig. 2). We hypothesize that normal and mutant Fbn 1 proteins are synthesized in Tsk/+ mice. Because Fbn1 is a secreted protein, the presence of 984 additional amino acids might affect intracellular folding before secretion. Thus, if secretion is impaired, one mechanism by which the mutant protein may act is by accumulating within cells. However, the finding of massive amounts of microfibrils that lacked periodicity in Tsk/+skin (Green et al. 1976) coupled with the disorganization and fragmentation of elastic fibers seen in Tsk/+ lungs (Gardi et al. 1989; Akita et al. 1992), suggests that Fbn1 secretion and incorporation into extracellular microfibrils is not grossly impaired. Therefore, we predict that the mutant Fbn1 protein is incorporated into microfibrils along with normal Fbn1 protein. Some of the phenotypic alterations in $T s k /+$ mice might then arise because the mutant protein alters microfibril assembly, structure, function, and/or degradation.

Expression of $F b n 1$ must occur on or before day 8 of development to account for the in utero death of $T s k / T s k$ embryos. In situ hybridizations of sectioned mouse embryos showed that Fbn1 was expressed at 8.5 days by mesometrial cells in the decidua and endocardial cells in the embryo 
SIRACUSA ET AL.

$a$

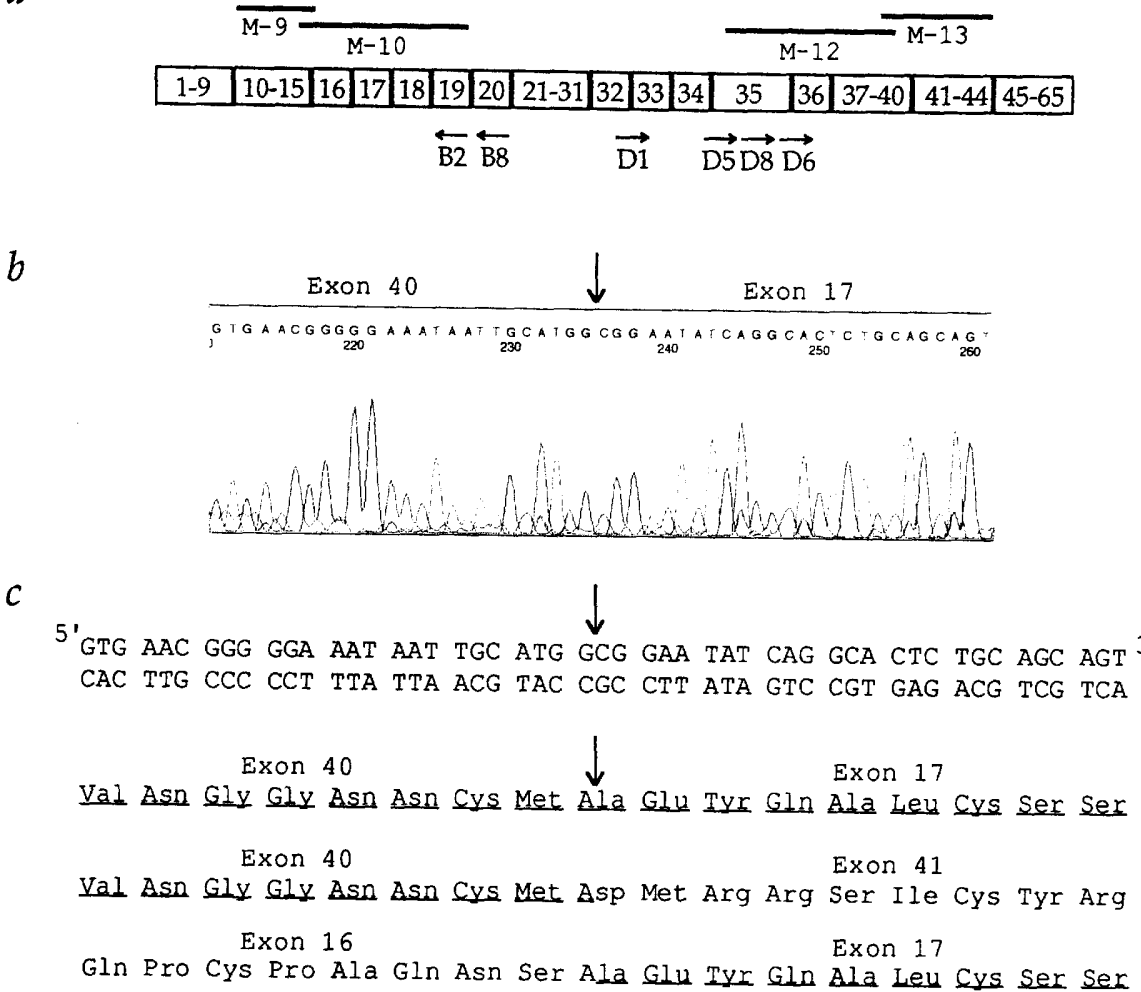

Figure 5 Sequence analysis of the junction fragment within the $F b n 1$ transcript. (a) Diagram of the 65 exons comprising Fbn1 mRNA (Pereira et al. 1993; Yin et al. 1995a). The probes that identified Tsk-specific restriction fragments are shown above the exons. The primers used for the RT-PCR reaction to identify the duplication breakpoint fragment in the mRNA of $T s k /+$ mice are indicated by arrows and shown below the exons. Primer $B 8$ was used for the RT reaction. Primer pairs D1 and B2, D5 and B2, D8 and B2, and D6 and B2 each amplified a unique fragment in mRNA from B6 $p a+/+$ Tsk mice but not B6 $p a+/$ $p a+$ mice. (b) RT of B6 pa+l+ Tsk mRNA with primer B8 followed by PCR with primers D6 and B2 produced an 870-bp Tsk-specific product. Sequencing revealed a unique junction between bp 5065 and 2113 of the Fbn1 cDNA corresponding to a junction between the end of exon 40 and the beginning of exon 17 (shown by the arrow). The sequence of the region immediately surrounding the junction point is shown. (c) The top line shows the same nucleotide sequence as in $B$, but in the double-stranded form. Below the nucleotide sequence, the underlined amino acids show the deduced translation product of the mutant protein. The last two lines show the translation of exons $40-41$ and exons 16-17 in normal $F b n 1$ with the underlined residues in exon 40 and 17 being present in the mutant protein. The alanine residue encoded by the junction point is a one-third split codon from exon 40 that joins the two-thirds split codon from exon 17 . The junction leaves the open reading frame perfectly intact.

(Yin et al. 1995a). Fbn1 protein was detected by immunolabeling in Henson's node and the primitive groove of stage 3 avian embryos (Gallagher et al. 1993), which correspond to preimplantation stages in mouse development. FBN1 is expressed at the eight-cell stage in human embryos (Eldadah et al. 1995) and preliminary results suggest that $F b n 1$ is expressed beginning at the eight-cell stage in mouse embryos (J. Manne, R. McGrath, J. Rothstein, and L.D. Siracusa, unpubl.). Thus, Fbn1 expression in mammalian embryos occurs before the time of death of Tsk/Tsk embryos (Green et al. 1976) and could account for the recessive lethality.

Our finding of a duplication within the Fbn1 gene on the Tsk chromosome stands in contrast to a previous report of recombination between the Fbn1 gene and the Tsk mutation (Doute and Clark 1994). We have shown that there were no recombinants between the Fbn 1 duplication and the Tsk phenotype in 330 mice, whereas Doute and Clark (1994) reported 2 of 130 recombinants between Fbn1 and Tsk in a backcross of [(B6 pa Tsk $a / p a+a \times$ Mus spretus ++ $A$ / $\left.++A) \mathrm{F}_{1} \times \mathrm{B} 6 p a+a / p a+a\right]$ mice. The $z$-test statistic for the difference between two population proportions (Daniel 1991) reveals that our data $(0 / 330)$ is significantly different from that previously reported $(2 / 130)$ with a probability of $P<$ 0.013 . The two recombinants observed by Doute and Clark were wild-type in phenotype, but homozygous for the C57BL/6J allele at the Fbn1 locus. The previous report of crossover events may be explained by intragenic recombination, detection of related sequences or pseudogenes, the influence of modifier loci in the interspecific backcross masking the effects of the Tsk mutation or a mistyping of the phenotype in the two recombinant mice. Our data indicate that the Fbn1 duplication lies 0-0.9 cM (95\% confidence limits) from the Tsk mutation. Although our data remain concordant with the Fbn1 duplication being the source of 
IANDEM DUPLICATION OF FBNI GENE IN TSK MICE

A

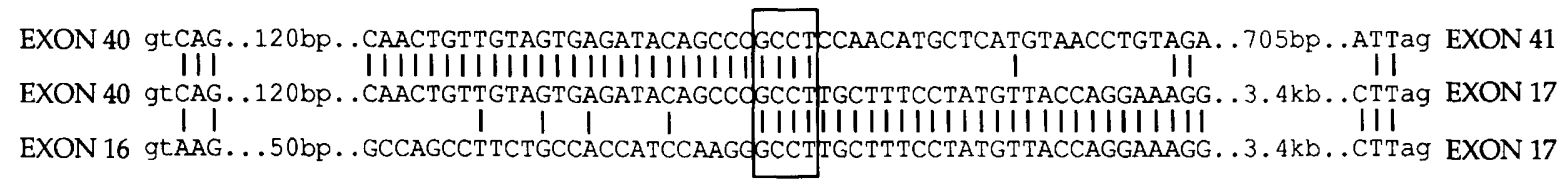

B

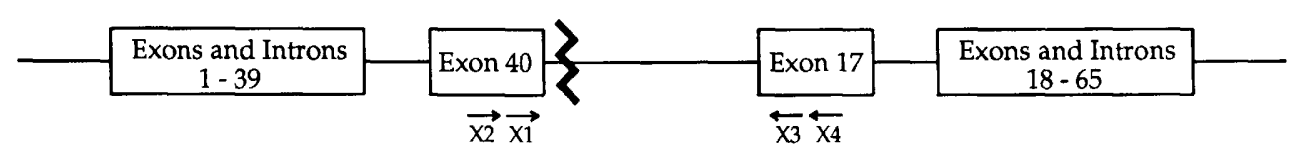

Figure 6 Tandem duplication within $F b n 1$ involves recombination between introns 40 and 16. (A) Intron sequences between exons 40 and 41 (top line), exons 16 and 17 (bottom line), and the duplication breakpoint within introns 40 and 16 (middle line). The box highlights the $4 \mathrm{bp}$ that are identical in both exons and the region within which the break occurred. Lowercase letters show that the splice donor site at the 3 ' end of exon 40 and the splice acceptor site at the $5^{\prime}$ end of exon 17 have remained intact in the Tsk chromosome. (B) Diagram of the Tsk chromosome highlighting the intron/exon structure of the mutant $F b n 1$ gene, the duplication breakpoint (jagged line), and the primers used for genomic amplification (X1,X2, X3, and X4). PCR primer pairs $X 2$ and $X 3$, $X 2$ and $X 4, X 1$ and $X 3$, and $X 1$ and $X 4$ each amplified independently the junction fragment in $B 6 p a+/+$ Tsk mice, which was not detected in $\mathrm{B} 6 p a+/ p a+$ mice.

the Tsk mutation, we cannot exclude the possibility of a second mutation in Fbn1 or a tightly linked gene contributing to the Tsk phenotype.

\section{Comparison of Fbnl Mutations in MFS Patients and the Tsk Mouse}

The variety of FBN1 mutations in patients with MFS are providing a foundation for understanding the relationship between genotype and the variability and severity of clinical manifestations. The mutations include (1) genomic deletions and nonsense mutations that induce exon skipping, resulting in shortened or truncated FBN1 proteins, (2) nonsense mutations that result in decreased levels of mutant FBN1 transcripts, and (3) missense mutations that alter FBN1 protein function (Dietz et al. 1991, 1992a,b, 1993a,b; Kainulainen et al. 1992, 1994; Kielty et al. 1995; Nijbroek et al. 1995). Studies of FBN1 synthesis and secretion in cultured fibroblasts have revealed potential mechanisms by which FBN1 mutations result in MFS (Aoyama et al. 1993, 1994; Kielty et al. 1994, 1995). The mechanisms include the mutant protein (1) interfering with FBN1 secretion, (2) decreasing the rate of fibrillin aggregation, (3) interfering with normal microfibril assembly, (4) being incorporated into microfibrils along with normal protein, disrupting microfibril structure and function, and (5) decreased levels of mutant $F B N 1$ transcripts resulting in low levels of FBN1 protein, causing a reduction in the amount of microfibrils. Most of these mechanisms involve the mutant FBN1 protein acting in a dominantnegative fashion to cause disease.

The Tsk mutation represents the first tandem duplication reported for the Fbn1 gene. A comparison of phenotypes between patients with MFS and Tsk/+ mice shows distinct differences. The loose connective tissue of MFS patients (for review, see Godfrey 1993) is in contrast to the thickened dermis and fascia of Tsk/+ mice. Most MFS patients exhibit skin hyperextensibility (Grahame and Pyeritz 1995), whereas the skin of $T s k /+$ mice exhibits decreased elasticity. Skeletal alterations of MFS include a disproportionately elongated skeleton with long extremities, arachnodactyly, scoliosis, and joint hypermobility. $T s k /+$ mice have an enlarged but well-proportioned skeleton, with shortened tendons and hyperplasia of tendon sheaths (Green et al. 1976). The causes of morbidity and mortality in MFS patients are structural abnormalities in the cardiovascular system that include aortic root dilatation, mitral valve prolapse, aortic regurgitation, and aneurysms. In contrast, the hearts of Tsk/ + mice are enlarged attributable to myocardial fibrosis. Some MFS patients develop pulmonary emphysema (for review, see Godfrey 1993), whereas $T s k /+$ mice develop an emphysema-like condition with morphological distortion of lung tissue and progressive elastolytic changes (Szapiel 
SIRACUSA EI AL.

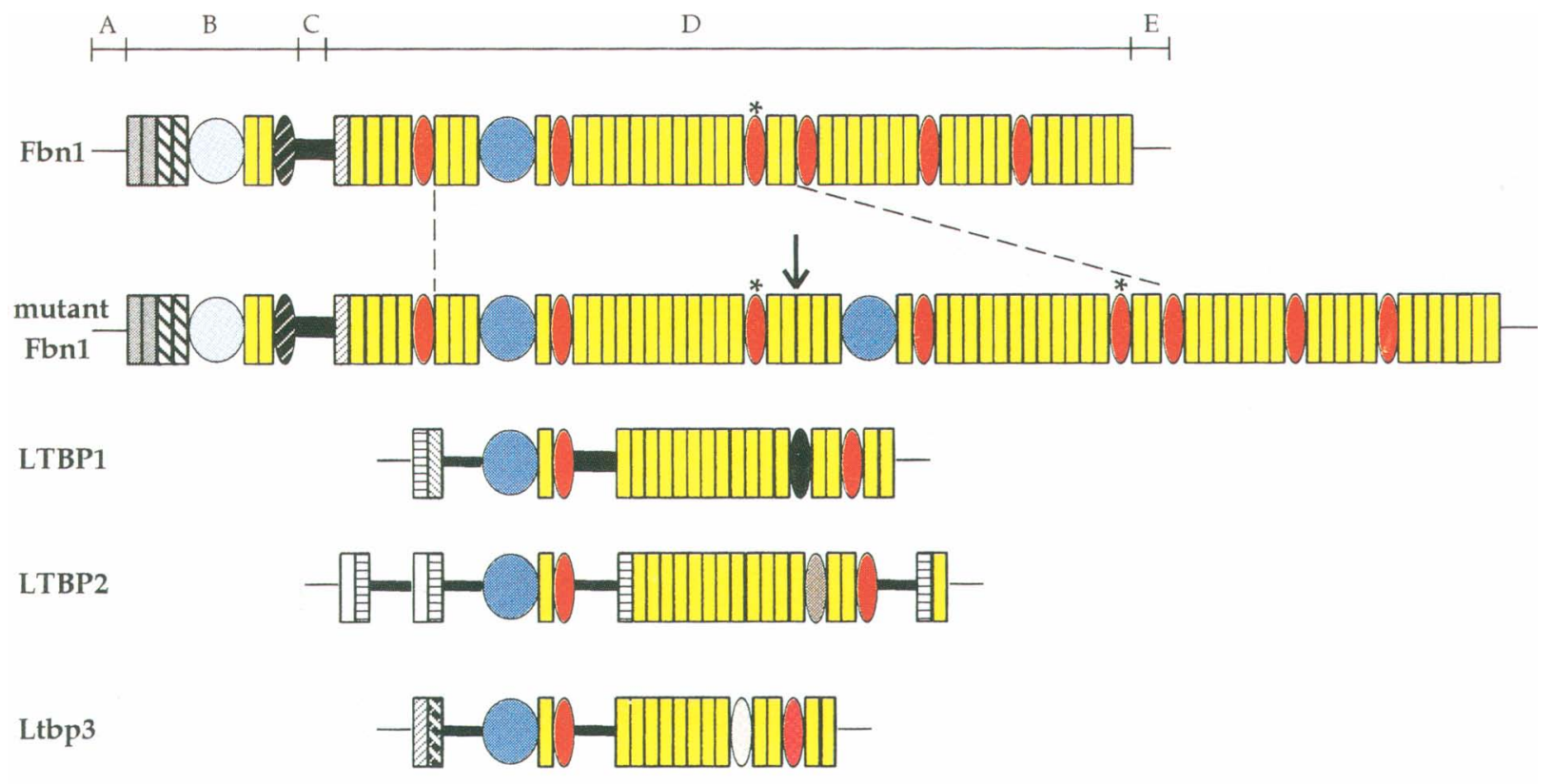

Figure 7 Schematic representation of protein motifs encoded by normal and mutant $F b n 1$ transcripts. Regions A-E indicate the five domains of the Fbn1 protein. "Fbn1" indicates the wild-type mouse Fbn1 protein and "mutant Fbn1" indicates the Tsk-specific protein. The dashed lines indicate the region duplicated in the Tskspecific transcript and the arrow indicates the single junction resulting from the duplication. The human "LTBP1", human "LTBP2", and mouse "Ltbp3" proteins represent the three related TGF- $\beta$-bp (Kanzaki et al. 1990; Moren et al. 1994; Yin et al. 1995b). Symbols represent the corresponding structural motifs: (patterned rectangles) cysteine-rich EGF-like repeats; (yellow rectangles) EGF-CB repeats; (dark blue circles) Fib motif; (light blue circles) Fib-like motif; (red ovals) TGF-bp repeats; (black shaded and patterned ovals) TGF-bp-like repeats; (asterisks) RGD domain; (thick bars) proline-rich region; (thin bars) proline/glycine-rich region; (very thin lines) amino- and carboxy-terminal amino acids. The only family member not shown is Fbn2 (Lee et al. 1991; Zhang et al. 1994).

et al. 1981; Rossi et al. 1984; Gardi et al. 1989; Martorana et al. 1989; Akita et al. 1992).

The dysfunction, disruption, or decrease of FBN1 deposition leads to MFS in humans. In comparison, Tsk was reported to cause an accumulation of abnormal microfibrils (Green et al. 1976) along with tissue fibrosis (for review, see Jimenez and Christner 1994). These findings suggest that although the Tsk-specific Fbn 1 protein may act in a dominant-negative fashion to disrupt microfibril structure and function, the mutant protein may also act as a gain-of-function mutation to induce a fibrotic response. Thus, alterations in Fbn1 can lead to a diverse range of disease phenotypes depending on the location and nature of the mutation (for review, see Godfrey et al. 1993; Ramirez et al. 1993; Kainulainen et al. 1994; Milewicz and Duvic 1994). This situation parallels mutations in other disease genes that produce distinct as well as overlapping clinical symptoms. Deciphering the mechanisms by which mutant Fbn 1 protein result in specific phenotypes in different tissues will provide insight into the biological roles of the Fbn1 gene.

\section{Contribution of a Mutant Fbnl Glycoprotein to Tsk Phenotypes}

The fibrillins have been proposed to regulate cellular activities and morphogenetic programs (Engel 1991; Gallagher et al. 1993; Yin et al. 1995a). If a mutant Fbn 1 protein (Fig. 7) is produced and secreted, then each additional domain may be contributing to the phenotypes exhibited by Tsk mice. The RGD domain anchors cells to the microfibrillar network and has a role in cell adhesion, migration, and differentiation (for review, see DeSimone 1994; Haas and Plow 1994). The presence of a second RGD domain could influence cell adhesion and/or cell shape by modifying integrin binding. Alternatively, altered integrin binding may lead to intracellular signals that govern a cascade of events resulting in increased extracellular matrix (ECM) synthesis. Alterations 
in integrin binding can also trigger autoimmune responses, and may be involved in the autoimmune abnormalities observed in $T s k /+$ mice (see below).

The TGF- $\beta$ family of proteins have roles in development, inhibition of cell proliferation, differentiation, wound healing, inflammation, and fibrosis (for review, see Massague 1990; Sporn and Roberts 1992; Kingsley 1994). The presence of additional TGF-bp domains in the mutant Fbn 1 protein may result in enhanced activity of TGF- $\beta$, a pleiotropic cytokine that has effects on most cell types. The Fbn 1 protein (Fig. 7) bears striking similarities to the latent Tgf- $\beta$-binding proteins LTBP1, LTBP2, and Ltbp3 (Kanzaki et al. 1990; Moren et al. 1994; Yin et al. 1995b). These proteins are part of large multiprotein complexes that bind intracellular TGF- $\beta 1$ and sequester its action until the latent complex is secreted and targeted to specific extracellular matrices (Miyazono et al. 1991; Taipale et al. 1994). Ltbp proteins have a critical role in the association of TGF- $\beta$ with the ECM and may also modulate the release of TGF- $\beta$ from the matrix (Taipale et al. 1994). The mutant Fbn1 protein may mimic the action of Ltbp proteins, resulting in excessive TGF- $\beta$ activity that can lead to the tissue fibrosis observed in $T s k /+$ mice.

The packing of fibrillin monomers and the structural integrity of microfibrils is dependent on calcium binding by EGF-calcium-binding (CB) domains (Corson et al. 1993; Kielty and Shuttleworth 1993; Handford et al. 1995). It is interesting that the region of $F b n 1$ duplicated in the Tsk chromosome includes the longest stretch of EGF-CB motifs, and mutations in neonatal lethal MFS are clustered within this same region (Kainulainen et al. 1994; Milewicz and Duvic 1994; Nijbroek et al. 1995). The functional significance of this region may rest not only with its importance for aggregation of fibrillin into microfibrils, but also with its ability to bind other proteins or growth factors that can convey signals to neighboring cells. In fact, the hypothesis proposed in the first report of the Tsk mutation states that "the Tsk mutation might produce an altered protein that binds with great affinity to a factor promoting growth of cartilage and connective tissue. .." (Green et al. 1976).

\section{The Tsk Mutation and Autoimmunity}

Mice carrying the Tsk mutation display autoimmune abnormalities (for review, see Jimenez and
IANDEM DUPLICAIION OF FBNI GENE IN ISK MICE

Christner 1994). However, immune dysregulation appears to occur subsequent to the development of tissue fibrosis in $T s k /+$ mice. Crosses placing the Tsk mutation on a CD4 - /- background (as opposed to a CD8 $-/$ - background) reveal that skin fibrosis, but not lung fibrosis, is lessened (Wallace et al. 1994), whereas making the Tsk mutation congenic on NZB, a strain prone to autoimmune disorders, exacerbates the fibrosis and autoimmune response (Bocchieri et al. 1993). Adoptive transfer experiments involving bone marrow and spleen cells have shown that skin fibrosis can be replicated in part, but the histopathology of lung disease cannot (Walker et al. 1989; Phelps et al. 1993). In addition, genetic crosses involving $T s k /+$ and $W$ mutant mice deficient for mast cells have shown that fibrosis precedes mast cell involvement (Everett et al. 1995). Thus, although autoimmunity may contribute to or exacerbate the fibrosis of $T s k /+$ mice, it may not be the primary cause of the fibrotic process. However, we cannot exclude the possibility that another cosegregating locus contributes to the autoimmune abnormalities exhibited by Tsk/ + mice. Transgenic animals that express mutant Fbn1 glycoproteins and mice that carry an Fbn1 gene knockout may resolve these issues and provide valuable models for the study of connective tissue diseases.

\section{METHODS}

\section{Mice}

Inbred mice of the CAST $+^{\mathrm{c}}++^{\mathrm{C}} /+^{\mathrm{c}}+{ }^{\mathrm{c}}, \mathrm{B} 6++/++, \mathrm{B} 6 p a+1$ $p a+, \mathrm{B} 6 p a+1+T s k, \mathrm{C} 57 \mathrm{BL} / 10 \mathrm{~J}, \mathrm{DBA} / 2 \mathrm{~J}$, and B10.D2(58N)/ Sn strains were purchased from The Jackson Laboratory (Bar Harbor, ME). Mice carrying Tsk and pa were maintained at the Jefferson Medical College (Philadelphia, PA). The intersubspecific backcross of [CAST $\times($ CAST $\times$ B 6 $\left.p a+1+T s k) \mathrm{F}_{1}\right]$ mice was as described (Siracusa et al. 1993). Only $\mathrm{N}_{2}$ progeny displaying the mutant $T s k$ phenotype, as determined by manual assessment of the thickness and tightness of the skin in the interscapular region, were used.

\section{Probes, Primers, and Mapping Analyses}

The human probes $\mathrm{H}-1, \mathrm{H}-3$, and $\mathrm{H}-4$ were generated by RT-PCR of human lung fibroblast RNA using primers based on the published human sequence (Maslen et al. 1991; Corson et al. 1993; Pereira et al. 1993). All primers are numbered based on the A of the initiation codon ATG as bp 1 . $\mathrm{H}-1$ primers were 5 '-TTAGCGTCCTACACGAGC-3' (182-200 bp) and 5'-AGTGATCGTCACTGCAGC-3' (551533 bp). H-3 primers were 5'-TTGCCGGAACACAATTGGTTCC-3' (5845-5866 bp) and 5'-ACGGTTGTCTTG- 


\section{SIRACUSA ET AL.}

TAAGTAGTCATAG-3' ${ }^{\prime}$ (6653-6629 bp). H-4 primers were 5'-GAGCTACAAGTGCATGTGTC-3' (8014-8033 bp) and 5'-CTCAACATTCTCGACTTCCTC-3' (8492-8471 bp). Poly $(\mathrm{A})^{+}$human lung RNA was a gift from Dr. Arturo Diaz (Jefferson Medical College, Philadelphia, PA). The H-2 probe was described previously (Lee et al. 1991; Goldstein et al. 1994). Probes M-8, M-9, and M-10 were prepared by PCR amplification of clone M- 6 using primer pairs 87 and B4, B3 and B6, and B1 and B2, respectively. Probes M-11, $\mathrm{M}-12$, and $\mathrm{M}-13$ were prepared by PCR amplification of clone M-7 using primer pairs D1 and D2, D6 and D7, and 61 and 62, respectively. The junction sequence was obtained by RT-PCR using the Superscript Preamplication System for First Strand Synthesis kit (GIBCO-BRL). The primer for the RT reaction was B8 5'-GCAGACAAAACTTCCAGGTGTGT-3' (2369-2346 bp); primers used for the PCR reaction were $\mathrm{B} 2$ 5' $^{\prime}$-AGGTAACAGTGTTTCATC-3' (2337$2320 \mathrm{bp})$ and D6 5'-GATTGGTATGAACTGGACCG-3' (4419-4439 bp), D8 5'-GGAACTTGGCACAAACCTC-3' (4375-4389 bp), D5 5'-GAAGATATCGATGAGTGCTCC-3' (4333-4353 bp), D1 5'-AAGTGCACAGATCTGG-3' (4078$4093 \mathrm{bp}$ ). Additional primers for these studies were $B 15^{\prime}$ ACAGATGCGAATGCTTCC-3' (1903-1921 bp), B3 5'AACAAGCTGTGCTCTG-3' (1156-1171 bp), B6 5'GGAAGCATTCGCATCTGT-3' (1921-1904 bp), D2 5'CAACACCGTTCAAGG-3' (4389-4374 bp), D7 5' GATTCCAGGAGTCTCACATTC-3' (4971-4951 bp), T2 5'GAATGTGAGACTCCTGGAATC-3' (4951-4971 bp), 61 5'CTCCTACAACATTCGCC-3' (5163-5184 bp), 62 5'CCAGTGTTGATGCATTCC-3' (5482-5465 bp), 87 5'GATATTGACGAGTGCAGC-3' (862-878 bp), and B4 5'CTCCTATAAGACCAGAG-3' (1207-1191 bp). Primers were prepared using an Applied Biosystems Model 394 DNA Synthesizer. The mapping of D2Mit19 and D2Mit63 was as described (Siracusa et al. 1993).

\section{Isolation of cDNA Clones and DNA Sequencing}

A 6- to 8-week-old $(\mathrm{B} 6 \times \mathrm{CBA}) \mathrm{F}_{1}$ female mouse lung cDNA library (Stratagene) was screened with the human cDNA probes ( $\mathrm{H}-1$ to $\mathrm{H}-4)$ hybridized at $64^{\circ} \mathrm{C}$ as described (Church and Gilbert 1984). Seven clones (M-1 to M-7) were isolated and sequenced from both directions using the Taq DyeDeoxy Terminator Sequencing kit (Applied Biosystems, Inc.) on an Applied Biosystems Model 373A DNA Sequencer.

\section{Southern and Northern blot Analyses}

Genomic DNA extractions, restriction endonuclease digestions, agarose gel electrophoresis, Southern blot transfer and washes were as described (Siracusa et al. 1989). Total RNA was isolated from mouse tissues using the guanidine isothiocyanate method (Chomczynski and Sacchi 1987) and size-fractionated by electrophoresis through $6.3 \%$ formaldehyde, $1.2 \%$ agarose gels in $1 \times$ MOPS running buffer (Sambrook et al. 1989). DNA and RNA was transferred to Hybond $\mathrm{N}+$ nylon membranes (Amersham) by blotting in $10 \times$ and $20 \times$ SSC, respectively. Membranes were hybridized (Church and Gilbert 1984) overnight at $65^{\circ} \mathrm{C}$, washed in $1 \times \mathrm{SSC}$ at $65^{\circ} \mathrm{C}$ for $1 \mathrm{hr}$, and exposed to Kodak XAR5 autoradiography film. Probes were ${ }^{32} \mathrm{P}$ labeled using a random prime kit (Boehringer Mannheim).

\section{Pulsed-field Gel Electrophoresis}

Agarose embedded single cell suspensions from spleen were prepared and digested with restriction endonucleases BssHII, EagI, NotI, and/or Nrul as described (Kingsley et al. 1992). Yeast and Lambda DNA-PFGE markers were the molecular weight size standards (Pharmacia). CHEF gels were $1 \%$ Rapid agarose (GIBCO-BRL) in $0.5 \times$ TBE and run in a pulsed-field system (C.B.S. Scientific) at $120-130 \mathrm{~V}$ for 40-42 hr. Gels were stained with EtBr, photographed, and nicked for $5 \mathrm{~min}$ at wavelength $254 \mathrm{~nm}$. Denaturation, neutralization, transfer, hybridization, and washing were as described above for Southern blots, except that the transfer lasted 2 days.

\section{Long-range PCR of genomic DNA}

Intron sequences were obtained by using Expand Long Template PCR System (Boehringer Mannheim). The guidelines for amplifying 0.5 - to 12 -kb products were used with $50 \mathrm{ng}$ of genomic DNA and the $10 \times$ buffer containing $17.5 \mathrm{~mm} \mathrm{MgCl}$. A single band was observed in every case and run on a $1 \%$ low melt gel in $0.5 \times \mathrm{TBE}$ at $90 \mathrm{~V}$. PCR products were excised, extracted, and sequenced as described above. Primers X6 5'-CCAAATCGGAATGCTGTTG$3^{\prime}(2036-2054 \mathrm{bp})$ and $\mathrm{X} 35^{\prime}$-CTGCAGAGTGCCTGATATTC-3' (2135-2116 bp) amplified wild-type intron 16, giving a $3.5-\mathrm{kb}$ product. Primers X 5 5'ACTACATGCAAGTGAACGG-3' (5030-5048 bp) and X7 5'-GTCTGGTTGTCAGCGTAATAG-3' (5114-5094 bp) amplified wild-type intron 40 , giving a $0.9-\mathrm{kb}$ product. Primers X1 5'-GTCCTCCAGACTACATGCAAGTG-3' (50215043 bp), X2 5' -ACCGTTGGCAACTATACCTGC-3' (4996$5016 \mathrm{bp}), X 3$, and $X 4$ 5'-ATCAGTGCCTGCTGATGTCATTCC-3' (2169-2146 bp) were used to amplify the breakpoint junction from the Tsk chromosome.

\section{ACKNOWLEDGMENTS}

We thank Dr. Arturo Diaz for the human lung RNA, Dr. Hansjuerg Alder for oligonucleotide synthesis and sequencing, and Jill Fisher for technical assistance. We are grateful to Drs. Joel Rosenbloom, Francesco Ramirez, Harry Dietz, Neal Copeland, Nancy Jenkins, and Aamir Zuberi for helpful discussions. Research supported by National Institutes of Health grants DK45717 to L.D.S. and AR32564 to S.A.J. L.D.S. is the recipient of an American Cancer Society Junior Faculty Research Award. J.J.M. is the recipient of a National Research Service Award training grant 1T32HL07780.

The publication costs of this article were defrayed in part by payment of page charges. This article must therefore be hereby marked "advertisement" in accordance with 18 USC section 1734 solely to indicate this fact.

\section{REFERENCES}

Akita, M., S.H. Lee, and K. Kaneko. 1992. Electron microscopic observations of elastic fibres in the lung and aorta of tight-skin and beta-aminopropionitrile-fed mice. Histol. Histopathol. 7: 39-45. 
Aoyama, T., K. Tynan, H.C. Dietz, U. Francke, and H. Furthmayr. 1993. Missense mutations impair intracellular processing of fibrillin and microfibril assembly in Marfan syndrome. Human Mol. Genet. 2: $2135-2140$.

Aoyama, T., U. Francke, H.C. Dietz, and H. Furthmayr. 1994. Quantitative differences in biosynthesis and extracellular deposition of fibrillin in cultured fibroblasts distinguish five groups of Marfan patients and suggest distinct pathogenetic mechanisms. J. Clin. Invest. 94: $130-137$.

Bashey, R.I., N. Philips, F. Insigna, and S.A. Jimenez. 1993. Increased collagen synthesis and increased collagen content of Type VI collagen in myocardium of Tight skin mice. Cardiovasc. Res. 27: 1061-1065.

Bocchieri, M.H., P.J. Christner, P.D. Henricksen, and S.A. Jimenez. 1993. Immunological characterization of (tight skin/NZB) F1 hybrid mice with connective tissue and autoimmune features resembling human systemic sclerosis. J. Autoimmunity 6: 337-351.

Chapman, D. and M. Eghbali. 1990. Expression of fibrillar types I and III and basement membrane collagen type IV genes in myocardium of tight skin mouse. Cardiovasc. Res. 24: 578-583.

Chomczynski, P. and N. Sacchi. 1987. Single-step method of RNA isolation by acid guanidinium thiocyanate-phenol-chloroform extraction. Anal. Biochem. 162: 156-159.

Church, G. and W. Gilbert. 1984. Genomic sequencing. Proc. Natl. Acad. Sci. 81: 1991-1995.

Cleary, E.G. and M.A. Gibson. 1983. Elastin-associated microfibrils and microfibrillar proteins. Int. Rev. Connect. Tiss. Res. 10: 97-209.

Corson, G.M., S.C. Chalberg, H.C. Dietz, N.L. Charbonneau, and L.Y. Sakai. 1993. Fibrillin binds calcium and is coded by cDNAs that reveal a multidomain structure and alternatively spliced exons at the 5 ' end. Genomics 17: 476-484.

D'Angelo, W.A., J.F. Fries, A.T. Masi, and L.E. Shulman. 1969. Pathologic observations in systemic sclerosis (scleroderma)-A study of 58 autopsy cases and 58 matched controls. Am. J. Med. 46: 428-440.

Daniel, W.W. 1991. Biostatistics: A foundation for analysis in the health sciences. John Wiley \& Sons, New York, NY.

DeSimone, D.W. 1994. Adhesion and matrix in vertebrate development. Curr. Opin. Cell Biol. 6: 747-751.

Dietz, H.C., G.R. Cutting, R.E. Pyeritz, C.L. Maslen, L.Y. Sakai, G.M. Corson, E.G. Puffenberger, A. Hamosh, E.J. Nanthakumar, S.M. Curristin, G. Stetten, D.A. Meyers, and C.A. Francomano. 1991. Marfan syndrome caused by a recurrent de novo missense mutation in the fibrillin gene. Nature 352: 337-339.

\section{TANDEM DUPLICATION OF FBNI GENE IN TSK MICE}

Dietz, H.C., R.E. Pyeritz, E.G. Puffenberger, R.J. Kendzior, G.M. Corson, C.L. Maslen, L.Y. Sakai, C.A. Francomano, and G.R. Cutting. 1992a. Marfan phenotype variability in a family segregating a missense mutation in the epidermal growth factor-like motif of the fibrillin gene. $J$. Clin. Invest. 89: 1674-1680.

Dietz, H.C., J.M. Saraiva, R.E. Pyeritz, G.R. Cutting, and C.A. Francomano. 1992b. Clustering of fibrillin (FBN 1) missense mutations in Marfan syndrome patients at cysteine residues in EGF-like domains. Hum. Mutat. 1: $366-374$.

Dietz, H.C., D. Valle, C.A. Francomano, R.J. Kendzior, R.l. Pyeritz, and G.R. Cutting. 1993a. The skipping of constitutive exons in vivo induced by nonsense mutations. Science 259: 680-683.

Dietz, H.C., I. McIntosh, L.Y. Sakai, G.M. Corson, S.C. Chalberg, R.E. Pyeritz, and C.A. Francomano. 1993b. Four novel FBN1 mutations: Significance for mutant transcript level and EGF-like domain calcium binding in the pathogenesis of Marfan syndrome. Genomics 17: 468-475.

Doute, R.C. and S.H. Clark. 1994. Tight-skin (Tsk) maps on mouse chromosome 2 within the region of linkage homology with human chromosome 15 . Genomics 22: $223-225$.

Eldadah, Z.A., J.A. Grifo, and H.C. Dietz. 1995. Marfan syndrome as a paradigm for transcript-targeted preimplantation diagnosis of heterozygous mutations. Nature Med. 1: 798-803.

Engel, J. 1991. EGF-like domains in extracellular matrix proteins: Localized signals for growth and differentiation. FEBS Lett. 251: 1-7.

Esterly, N.B. and V.A. McKusick. 1971. Stiff skin syndromes. Pediatrics 47: 360-369.

Everett, E.T., J.L. Pablos, S.E. Harris, E.C. LeRoy, and J.S. Norris. 1994. The tight-skin (Tsk) mutation is closely linked to $\mathrm{B} 2 \mathrm{~m}$ on mouse chromosome 2. Mamm. Genome 5: $55-57$.

Everett, E.T., J.L. Pablos, R.A. Harley, E.C. LeRoy, and J.S. Norris. 1995. The role of mast cells in the development of skin fibrosis in tight-skin mutant mice. Comp. Biochem. Physiol. 110A: 159-165.

Gallagher, B.C., L.Y. Sakai, and C.D. Little. 1993. Fibrillin delineates the primary axis of the avian embryo. Dev. Dynam. 196: 70-78.

Gardi, C., P.A. Martorana, M.M. de Santi, P. van Even, and G.A. Lungarella. 1989. A biochemical and morphological investigation of the early development of genetic emphysema in Tight-skin mice. Exp. Mol. Pathol. 50: $398-410$.

Godfrey, M. 1993. The Marfan syndrome. In McKusick's heritable disorders of connective tissue, 5 th ed. (ed. P. 


\section{SIRACUSA ET AL.}

Beighton), pp. 51-135. C.V. Mosby, St. Louis, MO.

Goldstein, C., P. Liaw, S.A. Jimenez, A.M. Buchberg, and L.D. Siracusa. 1994. Of mice and Marfan: Genetic linkage analysis of the fibrillin ( $F b n 1$ and $F b n 2$ ) genes in the mouse genome. Mamm. Genome 5: 696-700.

Grahame, R. and R.E. Pyeritz. 1995. The Marfan syndrome: Joint and skin manifestations are prevalent and correlated. Br. J. Rheumatol. 34: 126-131.

Green, M.C., H.O. Sweet, and L.E. Bunker. 1976. Tight-skin, a new mutation of the mouse causing excessive growth of connective tissue and skeleton. Am. J. Pathol. 82: 493-511.

Haas, T.A. and E.F. Plow. 1994. Integrin-ligand interactions: A year in review. Curr. Opin. Cell Biol. 6: 656-662.

Handford, P., A.K. Downing, Z. Rao, D.R. Hewett, B.C. Sykes, and C.M. Kielty. 1995. The calcium binding properties and molecular organization of epidermal growth factor-like domains in human fibrillin-1. J. Biol. Chem. 270: 6751-6756.

Jablonska, S., H. Schubert, and I. Kikuchi. 1989. Congenital fascial dystrophy: Stiff skin syndrome-A human counterpart of the tight-skin mouse. J. Am. Acad. Dermatol. 21: 943-950.

Jimenez, S.A. and P. Christner. 1994. Animal models of systemic sclerosis. Clin. Dermatol. 12: 425-436.

Kainulainen, K., L.Y. Sakai, A. Child, F.M. Pope, L. Puhakka, L. Ryhanen, A. Palotie, I. Kaitila, and L. Peltonen. 1992. Two mutations in Marfan syndrome resulting in truncated fibrillin polypeptides. Proc. Natl. Acad. Sci. 89: 5917-5921.

Kainulainen, K., L. Karttunen, L. Puhakka, L. Sakai, and L. Peltonen. 1994. Mutations in the fibrillin gene responsible for dominant ectopia lentis and neonatal Marfan syndrome. Nature Genet. 6: 64-70.

Kanzaki, T., A. Olofsson, A. Moren, C. Wernstedt, U. Hellman, K. Miyazono, L. Claesson-Welsh, and C.H. Heldin. 1990. TGF- $\beta 1$ binding protein: A component of the large latent complex of TGF- $\beta 1$ with multiple repeat sequences. Cell 61: 1051-1061.

Kielty, C.M. and C.A. Shuttleworth. 1993. The role of calcium in the organization of fibrillin microfibrils. FEBS Lett. 336: 323-326.

Kielty, C.M., J.E. Phillips, A.H. Child, F.M. Pope, and C.A. Shuttleworth. 1994. Fibrillin secretion and microfibril assembly by Marfan dermal fibroblasts. Matrix Biol. 14: 191-199.

Kielty, C.M., T. Rantamaki, A.H. Child, C.A. Shuttleworth, and L. Peltonen. 1995. Cysteine-to-arginine point mutation in a "hybrid" eight-cysteine domain of FBN1: Consequences for fibrillin aggregation and microfibril assembly. J. Cell Sci. 108: $1317-1323$.

Kingsley, D.M. 1994. The TGF- $\beta$ superfamily: New members, new receptors, and new genetic tests of function in different organisms. Genes \& Dev. 8: $133-146$.

Kingsley, D.M., A.E. Bland, J.M. Grubber, P.C. Marker, L.B. Russell, N.G. Copeland, and N.A. Jenkins. 1992. The mouse short ear skeletal morphogenesis locus is associated with defects in a bone morphogenetic member of the Tgf $\beta$ superfamily. Cell 71: $399-410$.

Lee, B., G. Maurice, V. Emilia, H. Hori, M. Mattei, M. Sarfarazi, P. Tsipouras, F. Ramirez, and D.W. Hollister. 1991. Linkage of Marfan syndrome and a phenotypically related disorder to two different fibrillin genes. Nature 352: 330-334.

Li, X., L. Pereira, H. Zhang, C. Sanguineti, F. Ramirez, J. Bonadio, and U. Francke. 1993. Fibrillin genes map to regions of conserved mouse/human synteny on mouse chromosomes 2 and 18. Genomics 18: 667-672.

Longhurst, P.A., B. Eika, R.E. Leggett, and R.M. Levin. 1992. Urinary bladder function in the tight-skin mouse. J. Urol. 148: 1611-1614.

Magenis, R.E., C.L. Maslen, L. Smith, L. Allen, and L.Y. Sakai. 1991. Localization of the fibrillin (FBN) gene to chromosome 15, bandq 21.1. Genomics 11: 346-351.

Marfan, A.B. 1896. Un cas de deformation congenitale des quatre membres plus prononcee aux extremities characterisee par l'allongement des os avec un certain degre d'aminicissement. Bull. Mem. Soc. Med. Hop. Paris 13: $220-226$.

Martorana, P.A., P. van Even, C. Gardi, and G. Lungarella. 1989. A 16-month study of the development of genetic emphysema in tight-skin mice. Am. Rev. Respir. Dis. 139: 226-232.

Maslen, C.L., G.M. Corson, B.K. Maddox, R.W. Glanville, and L.Y. Sakai. 1991. Partial sequence of a candidate gene for the Marfan syndrome. Nature 352: 334-337.

Massague, J. 1990. The transforming growth factor- $\beta$ family. Annu. Rev. Cell Biol. 6: 597-641.

Medsger, T.A. 1993. Systemic sclerosis (scleroderma), localized scleroderma, eosinophilic fasciitis, and calcinosis. In Arthritis and allied conditions, 12th ed. (ed. D.J. McCarty and W.J. Coopman), pp. 1253-1292. Lea and Febiger, Philadelphia, PA.

Milewicz, D.M. and M. Duvic. 1994. Severe neonatal Marfan syndrome resulting from a de novo 3-bp insertion into the fibrillin gene on chromosome 15. Am. J. Hum. Genet. 54: 447-453.

Miyazono, K., A. Olofsson, P. Colosetti, and C.H. Heldin. 1991. A role of the latent TGF-beta binding protein in 
the assembly and secretion of TGF-beta1. EMBO J. 10: $1091-1101$.

Moren, A., A. Olofsson, G. Stenman, P. Sahlin, T. Kanzaki, L. Claesson-Welsh, P. ten Dijke, K. Miyazono, and C.H. Heldin. 1994. Identification and characterization of LTBP-2, a novel latent transforming growth factor-beta-binding protein. J. Biol. Chem. 269: 32469-32478.

Nijbroek, G., S. Sood, I. McIntosh, C.A. Francomano, E. Bull, L. Pereira, F. Ramirez, R.E. Pyeritz, and H.C. Dietz. 1995. Fifteen novel FBN1 mutations causing Marfan syndrome detected by heteroduplex analysis of genomic amplicons. Am. J. Hum. Genet. 57: 8-21.

Osborn, T.G., R.I. Bashey, T.L. Moore, and V.W. Fischer. 1987. Collagenous abnormalities in the heart of the tight skin mouse. J. Mol. Cell. Cardiol. 19: 581-587.

Pereira, L., M. D'Alessio, F. Ramirez, J.R. Lynch, B. Sykes, T. Pangilinan, and J. Bonadio. 1993. Genomic organization of the sequence coding for fibrillin, the defective gene product in Marfan syndrome. Hum. Mol. Genet. 2: 961-968.

Phelps, R.G., C. Daian, S. Shibata, R. Fleischmajer, and C.A. Bona. 1993. Induction of skin fibrosis and autoantibodies by infusion of immunocompetent cells from Tight skin mice into $\mathrm{C} 57 \mathrm{BL} / 6 \mathrm{pa} / \mathrm{pa}$ mice. $J$. Autoimmunity 6: 701-718.

Putnam, E.A., H. Zhang, F. Ramirez, and D.M. Milewicz. 1995. Fibrillin-2 (FBN2) mutations result in the Marfan-like disorder, congenital contractural arachnodactyly. Nature Genet. 11: $456-458$.

Ramirez, F., L. Pereira, H. Zhang, and B. Lee. 1993. The fibrillin-Marfan syndrome connection. BioEssays 15: $589-594$.

Rossi, G.A., G.W. Hunninghake, J.E. Gadek, S.V. Szapiel, O. Kawanami, V.J. Ferrans, and R.G. Crystal. 1984. Hereditary emphysema in the tight skin mouse. Evaluation of pathogenesis. Am. Rev. Respir. Dis. 129: $850-855$.

Sambrook, J., E.F. Fritsch, and T. Maniatis. 1989. Molecular cloning: A laboratory manual. Cold Spring Harbor Laboratory Press, New York, NY.

Singer, H.S., D. Valle, J. Rogers, and G.H. Thomas. 1977. The stiff skin syndrome: New genetic and biochemical investigations. Birth Defects Orig. Art. Ser. 13: 254-255.

Siracusa L.D., P. Christner, R. McGrath, S.D. Mowers, K.K. Nelson, and S.A. Jimenez. 1993. The Tight skin (Tsk) mutation in the mouse, a model for human fibrotic diseases, is tightly linked to the B2-microglobulin gene on chromosome 2. Mamm. Genome 17: 748-751.

Siracusa, L.D., A.M. Buchberg, N.G. Copeland, and N.A. Jenkins. 1989. Recombinant inbred strain and interspecific backcross analysis of molecular markers

\section{IANDEM DUPLICATION OF FBNI GENE IN ISK MICE}

flanking the murine agouti coat color locus. Genetics 122: 669-679.

Sporn, M.B. and A.B. Roberts. 1992. Transforming growth factor-beta: Recent progress and new challenges. J. Cell Biol. 119: 1017-1021.

Stevenson, R.E., T.L. Lucas, and J.B. Martin. 1984. Symmetrical lipomatosis associated with stiff skin and systemic manifestations in four generations. Proc. Greenwood Genet. Center 3: 56-64.

Szapiel, S.V., J.D. Fulmer, G.W. Hunninghake, N.A. Elson, O. Kawanami, V.J. Ferrans, and R.G. Crystal. 1981. Hereditary emphysema in the tight-skin $(\mathrm{Tsk} /+)$ mouse. Am. Rev. Respir. Dis. 123: 680-685.

Taipale, J., K. Miyazono, C.H. Heldin, and J. Keski-Oja. 1994. Latent transforming growth factor-beta 1 associates to fibroblast extracellular matrix via latent TGF-beta binding protein. J. Cell Biol. 124: 171-181.

Walker, M.A., R.A. Harley, F.A. DeLustro, and E.C. LeRoy. 1989. Adoptive transfer of tsk skin fibrosis to $+/+$ recipients by tsk bone marrow and spleen cells. Proc. Soc. Exp. Biol. Med. 192: 196-200.

Wallace, V.A., S. Kondo, T. Kono, Z. Xing, E. Timms, C. Furlonger, E. Keystone, J. Gauldie, D.N. Sauder, T.W. Mak, and C.J. Paige. 1994. A role for CD4 + T cells in the pathogenesis of skin fibrosis in tight skin mice. Eur. J. Immunol. 24: 1463-1466.

Yin, W., E. Smiley, J. Germiller, C. Sanguineti, T. Lawton, L. Pereira, F. Ramirez, and J. Bonadio. 1995a. Primary structure and developmental expression of $F b n 1$, the mouse fibrillin gene. J. Biol. Chem. 270: 1798-1806.

Yin, W., E. Smiley, J. Germiller, R.P. Mecham, J.B. Florer, R.J. Wenstrup, and J. Bonadio. 1995b. Isolation of a novel latent transforming growth factor- $\beta$ binding protein gene (LTBP-3). J. Biol. Chem. 270: 10147-10160.

Zhang, H., S.D. Apfelroth, W. Hu, E.C. Davis, C. Sanguineti, J. Bonadio, R.P. Mecham, and F. Ramirez. 1994. Structure and expression of Fibrillin-2, a novel microfibrillar component preferentially located in elastic matrices. J. Cell Biol. 124: 855-863.

Received January 10, 1996; accepted in revised form March 4, 1996. 


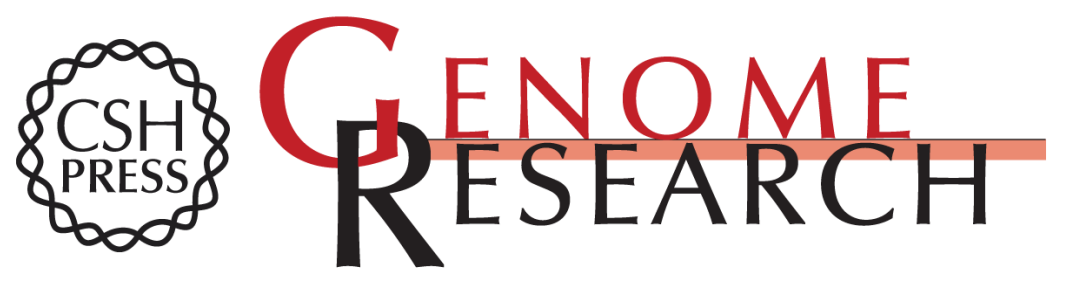

\section{A tandem duplication within the fibrillin 1 gene is associated with the mouse tight skin mutation.}

L D Siracusa, R McGrath, Q Ma, et al.

Genome Res. 1996 6: 300-313

Access the most recent version at doi:10.1101/gr.6.4.300

References This article cites 70 articles, 13 of which can be accessed free at:

http://genome.cshlp.org/content/6/4/300.full.html\#ref-list-1

\section{License}

Email Alerting Receive free email alerts when new articles cite this article - sign up in the box at the Service top right corner of the article or click here.

\section{Affordable, Accurate Sequencing.}

To subscribe to Genome Research go to:

https://genome.cshlp.org/subscriptions 